\title{
Uber: o mercado de transporte individual de passageiros - regulação, externalidades e equilíbrio urbano
}

Conselho Administrativo de Defesa Econômica (Cade)

\author{
Luiz Alberto Esteves*
}

\section{Sumário executivo}

O presente trabalho é um primeiro esforço do Departamento de Estudos Econômicos do Cade (DEE/Cade) no objetivo de obter melhor compreensão dos mercados de transporte individual de passageiros, mais especificamente para os mercados de táxis e de caronas pagas. Todas as opiniões aqui expressas são pessoais e não representam posicionamento oficial do Conselho Administrativo de Defesa Econômica - Cade. Conforme o art. 17 da Lei 12.529 de 30 de novembro de 2011, o DEE/Cade fica incumbido de "elaborar estudos e pareceres econômicos, de ofício ou por solicitação do Plenário, do Presidente, do Conselheiro-Relator ou do Superintendente-Geral, zelando pelo rigor e atualização técnica e científica das decisões do órgão". O presente

\footnotetext{
* Economista-chefe do Cade.
} 
trabalho é parte integrante do processo 08700.008971/2015-15, instaurado de ofício por este Departamento.

O texto é formado por cinco seções, incluindo o presente sumário executivo. A segunda seção contextualiza o debate trazido pela inovação no setor de transporte individual acerca de aspectos concorrenciais, regulatórios e de planejamento urbano. A terceira seção é destinada a analisar o mercado de transporte individual de passageiros sob a ótica da análise de equilíbrio parcial, onde será apresentada uma breve revisão da literatura sobre a regulação dos mercados de táxis, uma discussão sobre evidências empíricas recentes que têm desafiado os planejadores urbanos e uma discussão sobre a teoria e a prática na desregulamentação destes mercados. A quarta seção analisa o mercado de transporte individual de passageiros sob a ótica do equilíbrio urbano, ou seja, como a estrutura do trânsito e do transporte individual de passageiros interfere em outras variáveis relevantes do espaço urbano. A quinta e última seção é dedicada a conclusões.

Desse debate infere-se que é necessário discutir a regulação do mercado de transporte individual de passageiros considerando aspectos de equilíbrio urbano. Sem embargo, conclui-se que não há elementos econômicos que justifiquem a proibição de novos prestadores de serviços de transporte individual. Para além disso, elementos econômicos sugerem que, sob uma ótica concorrencial e do consumidor, a atuação de novos agentes tende a ser positiva.

\section{Contextualização}

No dia 30 de junho de 2015, a Câmara de Vereadores do Município de São Paulo aprovou, em primeira votação, um projeto de lei de autoria do Vereador Adilson Amadeu (PTB/SP), que veta a prestação de serviços de caronas pagas por meio do aplicativo Uber - um aplicativo de smartphones que serve como plataforma para o pareamento entre ofertantes e demandantes de caronas pagas. $\mathrm{O}$ projeto foi aprovado com ampla vantagem: foram 48 votos favoráveis e apenas um voto contrário.

No mesmo dia a Câmara Legislativa do Distrito Federal aprovou Projeto de Lei, de autoria do Deputado Distrital Rodrigo Delmasso (PTN/DF), que regulamenta a utilização de tais tipos de dispositivos no Distrito Federal. Na prática, contudo, o projeto regulador teria os mesmos efeitos da proibição imposta pelos vereadores de São Paulo, pois veta que motoristas sem licença 
de táxi ofereçam transporte pago em aplicativos como o Uber. Assim como qualquer tema ligado ao dia a dia das cidades, tais decisões foram objeto de grande controvérsia.

No dia 6 de agosto, o governador Rodrigo Rollemberg (PSB/DF) anunciou o veto ao Projeto de Lei do Distrito Federal; até esta data, o Projeto da cidade de São Paulo aguarda votação em plenário para ser submetido à avaliação da prefeitura.

O presente trabalho é um primeiro esforço do DEE/Cade no objetivo de obter melhor compreensão dos mercados de transporte individual de passageiros, mais especificamente para os mercados de táxis e de caronas pagas. A principal motivação para tais manifestações tem sido os possíveis desdobramentos, especialmente sobre a concorrência, acerca das decisões acima mencionadas.

A rivalidade exercida pelos serviços de caronas pagas tem sido interpretada pelos prestadores de serviços de táxi e por algumas autoridades regulatórias e legislativas como ilegal e desleal, trazendo como implicação decisões de proibição e banimento dos aplicativos e do próprio serviço de caronas pagas. Por outro lado, os prestadores de serviços de caronas pagas e grupos de consumidores têm alegado que a entrada no mercado de transporte individual de passageiros vem sendo bloqueada por meio de atividade lobista dos taxistas, viabilizada pela captura de autoridades reguladoras e legislativas.

Algumas autoridades antitruste já se manifestaram formalmente acerca de tal problema, que tem tido repercussão nas principais economias do mundo. Na América Latina, por exemplo, a autoridade antitruste mexicana (Comissión Federal de Competencia Económica) emitiu, em junho de 2015, um documento endereçado aos governadores de Estados, ao chefe do Distrito Federal e aos legisladores daquele país com algumas recomendações, para que os governos locais reconheçam os serviços de caronas pagas intermediados pelos aplicativos de smartphones e que não adotem medidas no sentido de proibir ou banir tais serviços.

Os argumentos da autoridade antitruste mexicana são representativos de uma parcela não negligenciável das opiniões proferidas por acadêmicos, gestores de políticas públicas e autoridades ao redor do mundo, ou seja, que aplicativos como o Uber endereçam de forma amplamente satisfatória vários dos problemas que originaram a regulação de táxis nas cidades, principalmente aqueles decorrentes da assimetria de informação nestes mercados. O presente trabalho traz uma apresentação sintética da regulação dos mercados de táxis e discute algumas especificidades de cada um de seus segmentos (pontos de 
táxi, circulação em vias e porta a porta por meio de chamadas telefônicas), além dos argumentos favoráveis e contrários à regulação de entrada e de preços.

Partindo desta ótica, não faria sentido restringir a entrada de caronas pagas mediadas pelos aplicativos, uma vez que tais serviços de fato providenciam um mecanismo de autorregulação bastante satisfatório, além de atender um mercado até então não abrangido (ou abrangido de forma insatisfatória) pelos táxis, e também providenciando rivalidade adicional ao mercado de transporte individual de passageiros. Em suma, as inovações poderiam endereçar amplamente os problemas regulatórios dos mercados de táxis, desde que os segmentos de rua fossem perdendo participação para o segmento porta a porta. ${ }^{1}$

O argumento acima é novamente sintetizado em decisão de Mandato de Segurança impetrado por um motorista usuário do aplicativo Uber contra autoridade coatora (presidente do Departamento de Transportes Rodoviários do Estado do Rio de Janeiro/RJ), proferida pelo juiz Bruno Vinícius da Rós Bodart nos autos do processo 0346273-34.2015.8.19.0001 da 1aㅡ Vara de Fazenda Pública do Rio de Janeiro:

(...) há indícios significativos de que a iniciativa estatal é fruto de captura regulatória e não está voltada à promoção do melhor interesse público. A rigor, a consistência jurídica da escolha proibitiva é frágil. De um lado, existe um serviço bem qualificado e cada vez mais utilizado pela sociedade. De outro, há a oposição ferrenha de governantes à atividade; oposição essa fomentada, é bom que se frise, por grupos de interesse que, afortunados pelas escassas permissões outorgadas, logram rendas extraordinárias na exploração do serviço.

Os benefícios ao interesse público seriam inegáveis, pois aumentariam o bem-estar da sociedade por diversos mecanismos: (i) o novo mercado proveria um substituto superior aos carros particulares para um determinado grupo de consumidores; (ii) o novo mercado proveria um substituto superior aos táxis

1 Na metade da década de 1990 o segmento porta a porta por meio de chamadas telefônicas representava cerca de $70 \%$ do mercado de táxis em países como Noruega e Suécia (ver BEKKEN, J.; LONGVA, F. (2003)). As participações dependem, evidentemente, de como os mercados são regulados, disponibilidades de pontos de táxis, se os diferentes segmentos são regulados de forma similar (single-tier system) ou específica (multiple-tier system) etc. 
para um segundo grupo de consumidores; (iii) o novo mercado rivalizaria com os táxis e com os carros particulares, o que poderia trazer reduções de preços nas corridas de táxis, no aluguel de carros de passeio e até mesmo nos preços dos carros novos e usados. Nem mesmo os profissionais do mercado de táxis (não proprietários das licenças) seriam prejudicados, pois poderiam inclusive (ex post) utilizar os serviços do aplicativo, ou (ex ante) arbitrar entre entrar no mercado de táxis ou no mercado de caronas pagas. ${ }^{2}$ Portanto, o movimento refratário das autoridades seria justificado pela captura regulatória, motivada pela manipulação do ambiente político por grupos lobistas em busca de rendas econômicas, ou seja, por conta de rent-seeking.

Já a evidência empírica disponível acerca da desregulamentação dos mercados de táxis em alguns países desenvolvidos (Irlanda, Nova Zelândia, Suécia, Noruega, Holanda, EUA e Canadá) a partir da década de 1980 apresentou o seguinte padrão de resultados (Bekken e Longva, 2003):

- Os requerimentos de qualidade tornam-se muito importantes à medida que a entrada e os preços são desregulamentados. Até mesmo requerimentos modestos de qualidade são capazes de criar barreiras à entrada;

- Os preços não necessariamente são reduzidos por conta da liberalização das tarifas. Ao contrário, estas parecem crescer em média e variância. Isso parece se dever ao fato das tarifas estarem suprimidas na regulação. As tarifas parecem aumentar mais onde a competição é menor, ou seja, nos pontos de táxi e nas áreas rurais. Na Noruega houve aumento de preços pós-desregulação tarifária em todas as 10 empresas operadoras analisadas, variando entre $4,3 \%$ e $21 \%$. O grande benefício da liberação tarifária é a diversificação dos serviços prestados. Os aumentos e reduções de preços durante diferentes períodos tendem a seguir a lógica do equilíbrio entre oferta e demanda;

- A oferta de táxis tende a crescer quando as restrições de entrada são removidas. Os entrantes individuais focam nos segmentos de ponto e circulação em vias, mesmo porque no segmento de porta a porta a tendência é ampliação da oferta pelos operadores já existentes. No que diz respeito ao aumento de táxis pós-desregulação de entrada, cidades norte-americanas apresentaram crescimento entre 18\% (Kansas City, 1983/1984) e 127\% (San Diego, 1979);

2 FREITAS, P. (2015). Quem ganha e quem perde com a liberação dos táxis? Brasil: economia e governo. Mimeo. 
- Caso as tarifas continuem a ser reguladas após a desregulamentação da entrada, o setor de transporte privado individual de passageiros (caronas pagas, por exemplo) continuaria a operar como um complemento aos táxis no segmento porta a porta por meio de chamadas telefônicas;

- Processos de desregulamentação graduais parecem ter gerado melhores resultados que processo de desregulamentação simultâneo de entrada e tarifas. Isso ocorre por conta dos efeitos inesperados causados pelas mudanças regulatórias. O processo de desregulamentação do mercado de táxis na Holanda é considerado um exemplo bem-sucedido, ${ }^{3}{ }^{4}$ embora se tenha uma avaliação de que nem todos os seus objetivos tenham sido plenamente alcançados; ${ }^{5}$

- A perda de qualidade da frota de veículos não parece estar associada à livre entrada, assim como uma regulação muito forte não parece ser capaz de evitar deterioração da qualidade dos serviços. Contudo, os padrões de qualidade dos serviços devem ser endereçados independentemente do modelo regulatório desejado.

Em suma, o modelo de equilíbrio parcial ${ }^{6}$ aplicado à questão da desregulamentação dos mercados de táxis é capaz de providenciar fatos estilizados condizentes com a realidade das alterações observadas nos mercados desregulamentados. Contudo, em outras situações, providenciam predições não observáveis empiricamente, como é o caso da redução esperada nos preços. Na prática, o que se observa é tanto um aumento dos preços quanto da variabilidade dos serviços prestados. Isso ocorre porque em geral é assumido que o agente regulador estabelece preços corretos de equilíbrio, sendo que, em verdade, na maioria dos casos avaliados pela literatura, os preços máximos represavam potenciais aumentos.

Uma forma de suplantar alguns problemas na avaliação dos impactos de modificações nos mercados de transporte individual de passageiros é por meio da análise de equilíbrio urbano, visto que a análise de equilíbrio

3 BEKKEN, J.; LONGVA, F. (2003). Impact of taxi market regulation. TOI Report. Oslo, Norway.

4 OECD (2007). Taxi services: competition and regulation. Policy Roundtables. DAF/COMP (2007) 42.

5 BAANDERS, A.; CANOY, M. (2010). Ten years of taxi deregulation in the netherlands - the case for re-regulation and decentralization. European Transport Conference, 2010 Proceedings.

6 A análise de equilíbrio parcial envolve a noção de que os preços e quantidades de equilíbrio em um dado mercado são obtidos independentemente de outros mercados. Para o caso aqui analisado, isso significa que os preços e quantidades comercializados no mercado de transporte individual de passageiros não são influenciados e nem influenciam preços e quantidades de outros mercados. 
parcial desconsidera um elemento teórico básico da literatura sobre economia urbana: ${ }^{7}$ as variações nos custos de deslocamento dentro das áreas urbanas podem alterar (direta e/ou indiretamente) a configuração das cidades, bem como o uso e a ocupação do solo urbano. Em suma, podem afetar outras variáveis relevantes do espaço urbano, tais como os preços dos imóveis, dos aluguéis residenciais e até mesmo a taxa de crescimento e espraiamento das cidades (sprawl urbano).

Como discutido em parágrafos anteriores, um resultado esperado da legalização dos serviços de caronas pagas ou da desregulamentação dos mercados de táxi seria a redução generalizada dos custos de deslocamento dentro das cidades ${ }^{8}$ (embora isso nem sempre ocorra na prática). Analisando tal fato pela ótica do modelo neoclássico de economia urbana, as implicações econômicas de tais medidas iriam muito além daquelas sugeridas pela análise de equilíbrio parcial.

Nos casos específicos das reduções de custos de deslocamentos, o modelo teórico neoclássico prescreve um aumento do tamanho da cidade (este ponto será visto em detalhes nas próximas seções), ou seja, um aumento do sprawl urbano (espraiamento urbano). A relação entre o custo de deslocamento nas cidades e o sprawl urbano é tão reconhecida na literatura especializada que uma das principais recomendações dos economistas para a redução do sprawl urbano é a introdução de pedágios urbanos. Em termos práticos, significa elevar deliberadamente o custo do deslocamento das pessoas por meio de transporte individual de passageiros (públicos ou privados), de modo a evitar outros custos sociais, inclusive para gerações futuras. Aliás, como será discutido adiante, evidências empíricas e simulações com modelos de economia urbana de equilíbrio geral computável têm mostrado que pedágios urbanos são capazes de reduzir em até $10 \%$ o tamanho das cidades.

O ponto central nessa discussão é que economistas e planejadores urbanos têm considerado fortemente a hipótese de que a compactação das cidades (em oposição ao seu espraiamento) é uma forma mais eficiente e sustentável de alocar recursos escassos e de lidar com o uso e ocupação do solo urbano.

7 Mais especificamente o modelo neoclássico de economia urbana, conhecido na literatura especializada como "Modelo Alonso-Muth-Mills", que será discutido de forma sintética nas próximas seções.

8 O economista Mark Kleiman, por exemplo, divulgou um estudo em que conclui que nos bairros mais pobres de Los Angeles os carros do Uber atendem as chamadas na metade do tempo atendido por um táxi e suas corridas custam em média 50\% do valor das corridas de táxi. 
Embora não seja consensual, as políticas de compactação das cidades têm sido inclusive recomendadas por organismos internacionais, tais como $\mathrm{OCDE}^{9} \mathrm{e}$ Banco Mundial. ${ }^{10}$

Adicionalmente, sob a ótica da análise de equilíbrio urbano, o argumento da captura regulatória deveria ser relativizado. Isso ocorre pelo fato de que gestores urbanos não priorizam o transporte individual de passageiros, tampouco os mercados de táxis, que são considerados substitutos dos carros particulares, mas sim o transporte coletivo. Esses gestores têm focado suas políticas no sentido de criar incentivos para que as pessoas substituam o transporte individual de passageiros (públicos ou privados) por transporte coletivo. Neste sentido, os gestores urbanos manipulam "carrots $\mathcal{E}$ sticks", ou seja, buscam reduzir custos pecuniários (subsídios) e de oportunidade (aumento na velocidade de deslocamento) dos transportes coletivos e imputam custos adicionais aos veículos que servem de transporte individual de passageiros, tais como impostos sobre propriedade de veículos, taxas, seguros, pedágios urbanos, não utilização de linhas e canaletas exclusivas para ônibus, rodízios de placas, restrição do número de licenças de táxi etc. Tais políticas não guardam nenhuma relação com captura no mercado de táxis.

Não será discutido aqui se cidades compactadas são mais eficientes e sustentáveis, se o sprawl urbano é realmente indesejável ou se dever-se-ia buscar reduzir os incentivos de deslocamentos urbanos por meio de transporte individual (público ou privado) em favor de transportes coletivos. O fato é que tais temas são centrais na agenda de planejadores e economistas urbanos e desprezar tal fato pode implicar em potenciais distorções analíticas.

Olhando o problema sob a ótica do equilíbrio urbano, pode-se verificar que os enormes benefícios trazidos pela tecnologia dos aplicativos usados nos serviços de caronas pagas são altamente eficientes em mitigar os problemas de informação assimétrica nos mercados de táxi. Entretanto, sua capacidade de lidar com as preocupações dos planejadores urbanos (que incluem sprawl urbano e externalidades do consumo de transporte individual de passageiros) demanda estudos complementares.

Em suma, sob a ótica das políticas anti-sprawl, melhorar o bem-estar de um grupo de consumidores por conta da redução de seus custos de

9 Material disponível em: <www.oecd.org/greengrowth/greening-cities-regions/compact-city. htm>.

10 Material disponível em: <http://siteresources.worldbank.org/INTURBANDEVELOPMENT/ Resources/336387-1270074782769/Iuchi.pdf>. 
deslocamento por meio de transporte individual (público ou privado) não é condição necessária, nem suficiente, para que o conjunto da sociedade também desfrute de maior bem-estar, principalmente quando inferimos tais efeitos a partir de modelos de gerações sobrepostas. Isso ocorre porque o consumo de determinados bens pode gerar externalidades negativas, tais como poluição (sonora, visual, atmosférica, do solo e da água), congestionamento de bens públicos etc.

Por outro lado, mesmo reconhecendo o fato de que planejadores urbanos, economistas urbanos e legisladores locais persigam políticas anti-sprawl, o fato é que a proibição dos serviços de caronas pagas continua sendo economicamente injustificada, por dois motivos básicos:

- Como será visto adiante, a ciência econômica fornece um conjunto de elementos analíticos para a mensuração e a simulação de potenciais efeitos decorrentes de externalidades de consumo, bem como um rol de proposições de políticas públicas mitigadoras de tais efeitos, de modo que a proibição ou banimento de qualquer solução que traga aumento de bem-estar a um grupo de consumidores seria desnecessária e contraproducente;

- Não é possível descartar a hipótese de que os planejadores e economistas urbanos possam criar os incentivos necessários para que os mercados de caronas pagas operem de forma neutra-sprawl ou até mesmo em consonância com uma agenda anti-sprawl.

No que diz respeito ao primeiro tópico acima, podemos citar como exemplo a construção de modelos urbanos de equilíbrio geral computável, onde é possível simular (i) os efeitos adversos de algumas situações específicas e (ii) como diferentes políticas públicas poderiam mitigar tais efeitos. As políticas incluem introdução ou revisão de zoneamento urbano, taxação pigouviana (ou subsídios), ${ }^{11}$ pedágios urbanos etc. Tais ferramentas, associadas a informações coletadas em pesquisas de origem/destino (OD) e outras informações obtidas por meio de calibração de modelos de microssimulação de tráfego, fornecem a inteligência necessária para que os gestores de políticas públicas possam traçar suas estratégias e providenciar respostas mais sofisticadas do que proibições e banimentos a eventos disruptivos, ${ }^{12}$ como é o caso da introdução de tecnologias do tipo Uber.

11 Os impostos ou subsídios de Pigou são utilizados com o objetivo de corrigir imperfeições de mercado, tais como externalidades negativas decorrentes do consumo de alguns bens ou serviços.

12 Inovações disruptivas são caracterizadas, entre muitos fatores, por gerarem mudanças abruptas em modelos de negócio, além de atuarem como uma plataforma em um mercado de 
Já no que diz respeito ao segundo tópico, não é possível descartar a possibilidade de que um mercado bem estruturado de caronas pagas também possa contribuir com políticas anti-sprawl. Por exemplo, o mercado de caronas pagas é operacionalizado por meio de aplicativos de smartphones, logo tende a operar exclusivamente no segmento de transporte individual porta a porta (pre-booking), ou seja, não concorre com os espaços dedicados aos pontos de táxi (rank hiring) e nem circula pelas vias públicas em busca de passageiros (hailing). Caso o mercado de caronas pagas substitua uma fração significativa de carros particulares, que até então eram utilizados com o objetivo de transportar pessoas até seus locais de trabalho (geralmente nos centros), a demanda por estacionamentos nos centros das cidades tenderia a ser reduzida, abrindo assim espaço para um maior grau de adensamento nos centros urbanos, além de maior compactação das cidades.

Em suma, seria desejável que as autoridades reguladoras locais dispusessem dos instrumentos analíticos disponíveis nas engenharias, na arquitetura e urbanismo e na economia urbana para mensurar e lidar com os efeitos de inovações disruptivas que possam trazer implicações para o dia a dia das cidades. Por outro lado, também seria altamente desejável que as empresas responsáveis pela introdução de tais inovações trouxessem para as autoridades locais informações e estudos que reduzissem a assimetria de informação e buscassem endereçar uma agenda de discussão de forma a mitigar riscos e preocupações dos agentes públicos.

Os argumentos favoráveis à desregulamentação na livre entrada e saída no mercado de transporte individual de passageiros tendem a focar sobre os benefícios aos consumidores de tais tipos de serviços. Contudo, vários tipos de consumo geram externalidades, várias delas negativas, muitas das quais os consumidores sequer têm noção que existam. ${ }^{13} \mathrm{Na}$ ausência de um mundo

dois lados, ligando diversos fornecedores e consumidores. Portanto, garantem ao consumidor a oportunidade de desfrutar de substitutos imperfeitos para hotéis e táxis, por exemplo. A plataforma on-line tende a reduzir os custos de procura dos consumidores, ao mesmo tempo que permite que mais fornecedores possam entrar no mercado, ao reduzir barreiras à entrada. Portanto, pode-se concluir que tais plataformas melhoram a correspondência eficiente entre compradores e vendedores. Ao fazê-lo, tais plataformas entram em concorrência com segmentos onde incumbentes históricos oferecem serviços semelhantes.

13 Uma situação econômica envolve uma externalidade de consumo se o consumidor se preocupa diretamente com o consumo do outro agente. Exemplos: se cada família preferisse se locomover por meio de automóveis de grande porte, e outra família se sentisse prejudicada pelo veículo piorar o trânsito; se cada pessoa escolher por desfrutar de banhos prolongados, e outra se sentisse prejudicada pela redução no volume de água disponível; se uma família optar por não vacinar suas crianças e animais domésticos, e outra se sentir prejudicada por 
com imperfeições de mercado e externalidades de consumo, as autoridades locais e os legisladores deveriam dispor do mínimo de informações para tomada de decisão de como internalizar as externalidades. Por exemplo:

- Qual a previsão e a meta da frota de veículos operando no mercado de caronas pagas naquela cidade?

- Qual o impacto em termos de carros adicionais nas ruas? Seria apenas efeito substituição da frota já existente?

- Um carro dedicado a carona paga substituiria quantos carros particulares que tomariam espaço de estacionamentos nos centros urbanos?

- Caso adicione carros nas ruas, qual seria a estimativa de frota adicional? Quais serão as regiões da cidade mais afetadas? Qual a implicação em termos de consumo adicional de bens públicos? Haveria aumento de congestionamentos e de poluição ${ }^{14}$

- Caso haja o risco de aumentar a frota de veículos nas ruas, podendo implicar no aumento de congestionamentos e poluição, quem arcaria com o custo das externalidades de consumo dos serviços de caronas pagas?

- Seria possível acomodar potenciais efeitos adversos com o mero remanejamento do trânsito? Seriam necessários investimentos adicionais em infraestrutura viária?

- Seria necessário e/ou estratégico reformular o plano de zoneamento das cidades para acomodar o novo serviço ao menor custo social possível? Ou isso nem seria necessário, pois seus impactos seriam negligenciáveis?

As respostas para tais perguntas são fundamentais para a análise de custos e benefícios da autoridade local, inclusive para tratar de eventual desregulamentação do mercado de transporte individual de passageiros, pois a não internalização de potenciais externalidades tornaria o custo dos serviços de transporte individual de passageiros mais econômico do que o socialmente desejável, tornando a oferta do serviço desnecessariamente maior.

Deixando de lado a análise econômica de equilíbrios parcial e geral, verificamos que os eventos históricos sugerem que a trajetória dos transportes

estar mais vulnerável a vírus; se uma pessoa optar por promover festa com música em alto volume durante toda a madrugada e o vizinho ter preferência oposta sobre o silêncio etc. (VARIAN, H. Microeconomia: princípios básicos. 5. ed. Campus, 2000. cap. 32).

14 Algumas destas questões permanecem em aberto até mesmo em locais onde o Uber já opera a mais tempo, como é o caso de Nova Iorque. O economista Charles Komanoff tentou estimar o efeito da introdução de serviços de caronas pagas mediadas por aplicativos como Uber, Lyft e outros e chegou à conclusão de que estes foram responsáveis por uma redução de aproximadamente $7 \%$ na velocidade média de deslocamento naquela cidade. 
urbanos foi marcada por "public takeovers", 15 ou seja, tais serviços nasceram privados e se tornaram públicos por conta de suas imperfeições de mercado (assimetria de informação, externalidades etc.). A própria regulação de táxis foi instituída na cidade de Nova Iorque em resposta ao fato de que na Grande Depressão o número de táxis circulando pela cidade era de 30.000 (atualmente são um pouco mais de 13.000). Devido aos excessos da frota, os motoristas circulavam por longas horas nas ruas em busca de clientes, gerando vários problemas, tais como desgaste físico dos condutores e dos veículos, além dos congestionamentos. Por outro lado, a história mostra que a captura regulatória também esteve presente neste processo. ${ }^{16}$

O fato da história dos transportes urbanos ser marcada por "public takeovers" não significa que processos de desregulamentação não sejam bemsucedidos ou que não criem mercados saudáveis. Como visto ao longo do texto, a experiência de desregulamentação dos mercados de táxis providencia exemplos para todos os gostos e preferências, desde o fato de os mercados de táxis serem historicamente marcados por processos cíclicos de regulação e desregulamentação, ${ }^{17}$ até o bem-sucedido caso holandês - considerado benchmark na literatura especializada.

Como os casos bem-sucedidos e malsucedidos de desregulamentação coexistem na literatura, podemos inferir que o processo de "como fazer" tem papel fundamental em tais tipos de políticas. Contudo, o processo depende das especificidades e das idiossincrasias de cada um dos mercados a serem desregulamentados. Como será visto ao longo do texto, os mercados de táxis dependem muito de outras características das cidades, tais como o uso e ocupação do solo, a rede de transporte coletivo, as diferentes distribuições de densidade populacional em vários bairros etc. Portanto, uma norma regulatória transversal a ser aplicada indiscriminadamente em cidades heterogêneas deve ser considerada com a devida cautela.

Um dos argumentos que justifica o êxito do processo de desregulamentação do mercado de táxis na Holanda é que o processo foi gradual. De fato, mercados que geram externalidades tendem a ser regulados e configurados

15 VUCHIC, V. Urban transit: operations, planning and economics. Hoboken, New Jersey: John Wiley \& Sons, Inc., 2005.

16 HODGES, G. Taxi! A social history of the New York City cabdriver. Baltimore, Maryland: The John Hopkins University Press, 2007.

17 DEMPSEY, P. Táxi industry regulation, deregulation, and reregulation: the paradox of market failure. Transportation Law Journal, v. 24, n. 1, p. 73-120, 1996. 
com políticas do tipo "second best", ${ }_{18} 1920$ muitas vezes articuladas e interrelacionadas entre si. ${ }^{21}$ Parte da dificuldade do processo de barganha na eliminação regulatória decorre deste fato, o que gera evidente preocupação e incerteza para as autoridades, sem que isso tenha, novamente, qualquer relação com captura. Caso a literatura fosse unânime em apontar a desregulamentação como uma solução invariavelmente superior, de fato movimentos refratários decorreriam exclusivamente de captura, mas a evidência empírica disponível sugere não ser o caso.

Contudo, analisando em detalhe o caso holandês, talvez consigamos verificar outras virtudes, tal como a supermodularidade ${ }^{22}$ da estratégia. Os holandeses não apenas desregulamentaram o mercado de táxis, mas também criaram incentivos para que tal mercado operasse em consonância com as outras políticas urbanas. Por exemplo, o mercado de táxis foi estimulado a operar como um modal interligado à rede de transporte coletivo das cidades, contrapondo a lógica de que os táxis são substitutos dos veículos particulares e que concorrem com o transporte coletivo (argumento que tem sido desafiado pela evidência empírica recente). Em suma, os holandeses compatibilizaram os benefícios trazidos pela desregulamentação do mercado de táxis (análise de equilíbrio parcial) com os demais objetivos dos planejadores urbanos (análise de equilíbrio urbano).

\section{Análise de equilíbrio parcial}

\section{Mercado e regulação}

Os mercados de táxis têm um longo histórico de regulação e esta prática tem sido a regra, embora várias cidades importantes tenham experimentado diferentes formas de desregulamentação a partir da década de 1980.

18 BAUMOL, W. On taxation and the control of externalities. The American Economic Review, v. 62, n. 3, p. 307-322, 1972.

19 IPSEY, R. The general theory of second best. The Review of Economic Studies, v. 24, n. 1, p. 11-32, 1956.

20 MARKOVITS, R. Second-best theory and law \& economics: an introduction. Chicago-Kent Law Review, v. 73, n. 1, p. 3-10, 1998.

21 BENNEAR, L.; STAVINS, R. (2007). Second-best theory and the use of multiple policy instruments. Environmental and Resource Economics, v. 37, p. 111-129.

22 MILGROM, P.; ROBERTS, J. Complementarities and fit strategy, structure, and organizational change in manufacturing. Journal of Accounting and Economics, v. 19, n. 2-3, p. 179-208, 1995. 
A discussão acerca da desregulamentação de tais mercados é agora revigorada por conta do desenvolvimento de aplicativos para smartphones, que têm sido capazes de endereçar vários problemas que são comumente justificados para regulamentar o setor. ${ }^{23}$

Em primeiro lugar, faz-se necessário esclarecer que o mercado de táxis é geralmente dividido em três segmentos: (i) o segmento de pontos de táxi, conhecido na literatura internacional como táxi rank; (ii) o segmento de rua, conhecido na literatura como hailing; e (iii) o segmento porta a porta, também conhecido como pre-booking, taxi-booking ou phone booking, onde também operam os provedores de serviços de caronas pagas. Nem todas as cidades apresentam mercados com todos os tipos de segmentos.

A regulamentação dos mercados de táxi é principalmente motivada por conta das características dos segmentos de pontos de táxi e de rua, pois são exatamente nestes segmentos onde ocorrem as principais restrições e falhas de mercado. Em termos gerais os táxis são regulados para endereçar as seguintes preocupações:

- Segurança pública: envolve a proteção física dos consumidores, de terceiros e da adequação dos veículos. Isso implica estabelecer padrões mínimos de requerimento para os condutores e para os veículos;

- Proteção econômica dos consumidores: envolve prevenir os consumidores de incorrer em prejuízos em situações de barganha desproporcionalmente desvantajosa. Por exemplo, os taxistas cobrarem em uma condição de barganha favorável um preço significativamente maior do que cobrariam em uma situação com condições de barganha inferior;

- Congestionamentos: os táxis são regulados de forma a serem evitados maiores congestionamentos nos centros urbanos. Em muitas situações os mercados de táxi em centros urbanos são disciplinados para operarem por meio de pontos de táxi, de forma a não ficarem circulando em busca de passageiros. Deste modo as licenças de táxi podem ser racionadas conforme a disponibilidade de espaços urbanos para pontos de táxi;

- Desempenho: os reguladores podem manipular diferentes combinações de disponibilidade de pontos, tarifas máximas e número de licenças para alcançar um mercado que opere sob um grau de desempenho desejado.

23 Grande parte da discussão tratada nesta seção foi baseada nas seguintes referências bibliográficas: [1] BEKKEN, J.; LONGVA, F. Impact of taxi market regulation. TOI Report. Oslo, Norway, 2003; e [2] TONER, J. Regulation in the taxi industry. ITS Working Paper 381, Institute for Transport Studies, University of Leeds, Leeds, 1992. 
As autoridades, por sua vez, podem perseguir quatro tipos diferentes de políticas para seus mercados de táxi: (i) solução de mercado, onde não há qualquer regulação de entrada e preços; (ii) restrições de entrada, sem regulação de preços; (iii) entrada livre, com regulação de preços; e (iv) regulação de entrada e preços.

Os argumentos favoráveis à regulação da entrada incluem:

- A livre entrada implicaria em uma demanda excessiva por espaço em pontos de táxi;

- O custo de monitoramento da frota é elevado;

- Entrada excessiva reduziria a taxa de ocupação dos táxis, criando pressões para aumento dos preços para equilibrar os fluxos de receitas e despesas;

- A entrada de motoristas de tempo parcial pode criar uma oferta desproporcionalmente maior nos horários de pico ou em locais onde as corridas são mais atrativas (por exemplo, em aeroportos);

- Podem ser criadas pressões para aumento dos preços para atender aquelas corridas não atrativas para motoristas entrantes em tempo parcial.

Os argumentos contrários à regulação da entrada incluem:

- A regulação é cara;

- A regulação confere posições de poder e proteção;

- A regulação gera um prêmio para os detentores das licenças;

- Os controles aplicados ao mercado de táxi não são aplicados a outros mercados similares.

Os argumentos favoráveis à regulação de preços incluem:

- A estrutura espacial dos segmentos de pontos de táxi e de rua inibem competição de preços;

- A curva de demanda confrontada para cada consumidor é preço inelástica;

- O argumento da equidade: algumas regiões de uma cidade são mais atrativas que outras;

- Questão de ordem pública: a competição de preços entre os motoristas em um mesmo ponto de táxi seria física e praticamente inviável.

Os argumentos contrários à regulação de preços incluem:

- Outros mercados similares aos mercados de táxi não apresentam regulação de preços;

- A mensuração dos preços ótimos não é trivial e tende a gerar distorções na alocação dos recursos;

- Captura regulatória.

Como mencionado anteriormente, os segmentos de pontos de táxi e de rua tenderiam a despertar maiores preocupações aos reguladores, principalmente no que diz respeito à segurança física e econômica dos passageiros, 
além do fato destes segmentos demandarem muito espaço físico das cidades (destinado aos pontos de táxis) ou contribuírem de forma negativa para os congestionamentos (segmento de rua). Por conta disso, existem lugares onde a regulação dos segmentos éúnica (single-tier system) e outros onde a regulação do segmento porta a porta é diferente daquela aplicada aos segmentos de pontos e rua (two-tier system). ${ }^{24}$ Adicionalmente, os segmentos de pontos operam por meio de regras institucionais informais, do tipo filas com atendimento FIFO ("first-in-first-out"). Evidentemente que sob tais mecanismos um ponto de táxi ter uma fila com 30 veículos ou um único veículo torna completamente irrelevante qualquer processo de barganha.

Já o mercado porta a porta por meio de chamadas telefônicas é menos problemático em vários aspectos, uma vez que as empresas responsáveis pela coordenação da prestação de serviços podem criar mecanismos de autorregulação privada para aumentar a segurança do serviço, obter reputação de bom prestador de serviços, conceder descontos, além de incorrer em maior concorrência com outros prestadores do mesmo segmento. Adicionalmente, tal segmento tende a reduzir o problema de ocupação de espaços em pontos de táxi e circulação de veículos nas vias públicas em busca de passageiros.

Os desenvolvimentos tecnológicos dos aplicativos para smartphones, que incluem a possibilidade de visualizar o perfil dos motoristas e declinar da corrida, avaliar os serviços prestados, monitorar os deslocamentos do veículo por meio de tecnologia GPS, ter a precificação da corrida ex ante, além de efetuar o pagamento por meio eletrônico cadastrado na própria plataforma têm de fato endereçado várias das preocupações que motivaram historicamente a regulação de táxis.

Contudo, cabe destacar que os segmentos mais problemáticos do mercado de táxis são os de pontos de táxi e de rua. Isso significa que para essas novas tecnologias endereçarem de forma amplamente satisfatória os problemas regulatórios do setor como um todo, faz-se necessário que os mercados de pontos de táxi e de rua percam participação para o de chamadas telefônicas ao longo do tempo.

24 AARHAUG, J.; SKOLLERUD, K. Taxi: different solutions in different segments. European Transport Conference. Frankfurt, Germany, 2013. 


\section{O mercado de táxis revisitado}

Uma das principais prioridades dos gestores urbanos é o transporte coletivo, sendo que existe claro foco em políticas que possam gerar incentivos para que as pessoas substituam o transporte individual de passageiros (públicos ou privados) por transporte coletivo. Neste sentido, os gestores urbanos manipulam "carrots $\mathcal{E}$ sticks", ou seja, buscam reduzir custos pecuniários (tarifas) e de oportunidade (tempo de deslocamento) dos transportes coletivos e imputam custos adicionais aos veículos que servem de transporte individual de passageiros, tais como impostos sobre propriedade de veículos, taxas, seguros, pedágios urbanos, não utilização de linhas e canaletas exclusivas para ônibus, rodízios de placas, restrição do número de licenças de táxi etc.

O fato é que os gestores urbanos não priorizam o transporte individual de passageiros, tampouco os mercados de táxis, que são considerados substitutos dos carros particulares. Para o caso dos gestores urbanos em países em desenvolvimento, onde a infraestrutura de transporte coletivo é bastante limitada, alcançar seus objetivos é uma tarefa extremamente complexa e difícil, uma vez que o transporte coletivo de passageiros é considerado um substituto bastante inferior ao transporte individual até mesmo em países com as melhores infraestruturas de transporte urbano do mundo. ${ }^{25}$ Em suma, acompanhar a repercussão, a visibilidade e o volume de recursos materiais e humanos alocados para debater aspectos regulatórios do transporte individual de passageiros deve causar algum grau de frustração aos gestores urbanos.

Contudo, alguns estudos empíricos têm sugerido que os táxis exercem um papel mais importante para as redes integradas de transporte urbano do que se imaginava. De fato, as evidências têm mostrado que os táxis "jogariam mais a favor do que contra" o transporte coletivo. Dois estudos merecem destaque especial.

O primeiro trabalho empírico foi desenvolvido em 2012 por Juan Francisco Saldarriaga, na ocasião de seu mestrado em planejamento urbano da Universidade de Columbia, em Nova Iorque. Saldarriaga obteve uma amostra representativa de 200.000 viagens de táxi na cidade de Nova Iorque. Os resultados obtidos pelo autor podem ser visualizados em um vídeo

25 STEG, L. Can public transport compete with the private car? IATSS Research, v. 27, n. 2, p. 27-35, 2003. 
compartilhado no sítio eletrônico Vimeo, intitulado “New York City táxi activity: origin and destinations densities".${ }^{26} \mathrm{O}$ resultado mais desafiador da pesquisa é a assimetria observada nas densidades de origem e destinos no início da manhã e final da tarde. A interpretação dos resultados é fornecida por David King, professor de planejamento urbano da Universidade de Columbia, nos seguintes termos: se os táxis fossem substitutos quase-perfeitos dos veículos particulares, esperaríamos uma simetria nas densidades de origem e destino no início da manhã e final da tarde, assim como o efeito de uma imagem refletida em um espelho. Contudo, não é isso que podemos verificar no vídeo de Saldarriaga.

Tal fenômeno tem sérias implicações para a política de transporte urbano, conforme aponta King:

This matters because it means that individual's travel journeys are multimodal. If we want to have transit oriented cities we have to plan for high quality, door-to-door services that allow spontaneous one-way travel. Yet for all of the billions of dollars we have spent of fixed-route transit and the built environment we haven't spent any time thinking about how taxis (and related services) can help us reach our goals. ${ }^{27}$

Os resultados da pesquisa de Saldarriaga vão ao encontro do estudo empírico desenvolvido anteriormente por Schaller (2005), ${ }^{28}$ que desenvolveu um modelo econométrico aplicado a 118 cidades norte-americanas, cujo objetivo era verificar os principais fatores determinantes da demanda por táxis naquelas cidades. Schaller (2005) constata que a principal fonte de demanda para as viagens de táxi advém de trabalhadores que usam tais serviços para acessar as estações de metrô. A segunda fonte é de famílias com nenhum veículo e a terceira é de corridas para aeroportos.

Tal característica sugere que uma política de retenção de licenças pode, em alguma medida, operar no sentido oposto ao desejado pelos planejadores urbanos, ou seja, ao invés de reduzir os custos de deslocamentos por transporte coletivo, como é o caso do metrô, estaria criando um incentivo perverso

26 Visualizar no link: <https://vimeo.com/35433719>.

27 Ver: <www.citylab.com/commute/2012/02/táxis-part-transit-system/1133/>.

28 SCHALLER, B. A regression model of the number of taxicabs in U.S. cities. Journal of Public Transportation, v. 8, n. 5, p. 63-78, 2005. 
no sentido do público substituir a combinação modal "transporte individual mais transporte coletivo" por um transporte exclusivamente individual.

Tal fato sugere que a revisão da regulamentação de entrada nos mercados de táxis demande realmente uma análise pormenorizada. Contudo, o fato de uma das maiores demandas de viagens de táxis ser de pessoas se deslocando diariamente de suas casas para o trabalho (e não necessariamente de volta do trabalho para a casa, como foi visto nos resultados de Saldarriaga) pode ser um problema quando se trata de desregulamentação de tarifas, uma vez que a evidência empírica disponível sugere que tal tipo de desregulamentação tende a aumentar a variância dos preços das corridas (inclusive a depender do dia e horário da corrida). Supondo que os consumidores regulares sejam avessos ao risco, a introdução de tal medida sem a devida compensação pecuniária (redução do preço) pode deixar os consumidores em pior situação.

\section{Impacto da desregulamentação: teoria}

Como mencionado na seção anterior, o mercado de táxis é regulado em quase todos os países do mundo. Os formatos são os mais variados, mas a regulação mais restritiva inclui controle de preços, de oferta e de qualidade. Foi visto que vários dos problemas que justificam a regulação dos mercados de táxis têm sido endereçados de forma bastante satisfatória pelas novas tecnologias disponíveis nos aplicativos para smartphones. Isso tem viabilizado a entrada de novos ofertantes no mercado de transporte individual de passageiros, como é o caso dos motoristas de veículos de caronas pagas.

A rivalidade exercida pelos serviços de caronas pagas tem sido interpretada pelos prestadores de serviços de táxi e por algumas autoridades locais e legislativas como ilegal e desleal, trazendo como implicação decisões de proibição e banimento dos aplicativos e do próprio serviço de caronas pagas. Por outro lado, os prestadores de serviços de caronas pagas e grupos de consumidores têm alegado que a entrada no mercado de transporte individual de passageiros vem sendo bloqueada por meio de atividade lobista dos taxistas, viabilizada pela captura de autoridades reguladoras e legislativas.

Algumas autoridades antitruste já se manifestaram formalmente acerca de tal problema, que tem tido repercussão nas principais economias do mundo. Por exemplo, em junho de 2015 a autoridade antitruste mexicana (Cofece) emitiu um documento endereçado aos Governadores de Estados, ao Chefe do Distrito Federal e aos Legisladores daquele país com algumas recomendações, dentre elas destaco as que seguem: 
La normativa vigente en nuestro país no contempla esta nueva modalidad de servicios de transporte que deriva de los avances tecnológicos y de los esfuerzos de innovación. Como se ha expuesto con antelación, el desarrollo de aplicaciones móviles para el transporte de pasajeros resuelve problemas de asimetrías de información y problemas de coordinación entre conductores y pasajeros, contribuye a la movilidad urbana, fomenta la innovación y, en general, ofrece opciones eficientes de consumo que generan bienestar social. En consecuencia, esta COMISIÓN recomienda que se reconozca, a través de la vía que corresponda, una nueva categoría o modalidad para la prestación de este servicio innovador que tiene impacto relevante en la dinámica social.

Os argumentos da autoridade antitruste mexicana são representativos de uma parte não negligenciável das opiniões proferidas por acadêmicos, gestores de políticas públicas e autoridades ao redor do mundo, ou seja, que aplicativos como o Uber endereçam de forma amplamente satisfatória vários dos problemas que originaram a regulação de táxis nas cidades, principalmente aqueles decorrentes da assimetria de informação nestes mercados.

Neste sentido, os benefícios ao interesse público seriam inegáveis, pois aumentariam o bem-estar da sociedade por diversos mecanismos: (i) o novo mercado proveria um substituto superior aos carros particulares para um determinado grupo de consumidores; (ii) o novo mercado proveria um substituto superior aos táxis para um segundo grupo de consumidores; (iii) o novo mercado rivalizaria com os táxis e com os carros particulares, o que traria reduções de preços nas corridas de táxis, no aluguel de carros de passeio e até mesmo nos preços dos caros novos e usados. Nem mesmo os profissionais do mercado de táxis (não proprietários das licenças) seriam prejudicados, pois poderiam inclusive (ex post) utilizar os serviços do aplicativo, ou (ex ante) arbitrar entre entrar no mercado de táxis ou no mercado de caronas pagas. O movimento refratário das autoridades seria justificado pela captura regulatória, motivada pela manipulação do ambiente político por grupos lobistas em busca de rendas econômicas, ou seja, por conta de rent-seeking, nos moldes abordados por Tullock (1967) $)^{29}$ e Krueger (1974). ${ }^{30}$

29 TULLOCK, G. The welfare costs of tariffs, monopolies, and theft. Western Economic Journal, v. 5, n. 3, p. 224-232, 1967.

30 KRUEGER, A. The political economy of the rent-seeking society. American Economic Review, v. 64 , n. 3, p. 291-303, 1974. 
Adicionalmente, o poder de mercado garantido pelo racionamento de licenças comprometeria a qualidade dos serviços prestados pelos taxistas por conta de um mecanismo conhecido na literatura econômica como ineficiência-X. Trata-se de um conceito introduzido por Harvey Leibenstein, ${ }^{31}$ que sugere que as imperfeições de mercado possibilitam que os ofertantes incumbentes não busquem a maximização de eficiência e lucros, mas que possam acomodar de forma leniente algum grau de ineficiência por conta da ausência de pressões competitivas. Tal tipo de argumento tem sido utilizado de forma recorrente para justificar o fato de que os serviços prestados pelos taxistas apresentariam qualidade supostamente inferior ao prestado pelos motoristas de caronas pagas.

\section{Impacto da desregulamentação: prática}

Como já mencionado, o mercado de táxis iniciou-se historicamente privado, sofreu "public takeover" e vive ciclos de regulamentação e desregulamentação. Adicionalmente, a evidência empírica disponível acerca da desregulamentação dos mercados de táxis em alguns países desenvolvidos (Irlanda, Nova Zelândia, Suécia, Noruega, Holanda, EUA e Canadá) a partir da década de 1980 apresentou o seguinte padrão de resultados (Bekken e Longva, 2003):

- Os requerimentos de qualidade tornam-se muito importantes à medida que a entrada e os preços são desregulamentados. Até mesmo requerimentos modestos de qualidade são capazes de criar barreiras à entrada;

- Os preços não necessariamente são reduzidos por conta da liberalização das tarifas. Ao contrário, estas parecem crescer em média e variância. Isso parece se dever ao fato das tarifas estarem suprimidas na regulação. As tarifas parecem aumentar mais onde a competição é menor, ou seja, nos pontos de táxi e nas áreas rurais. Na Noruega houve aumento de preços pós-desregulação tarifária em todas as 10 empresas operadoras analisadas, variando entre $4,3 \%$ e $21 \%$. O grande benefício da liberação tarifária é a diversificação dos serviços prestados. Os aumentos e reduções de preços durante diferentes períodos tendem a seguir a lógica do equilíbrio entre oferta e demanda;

31 LEIBENSTEIN, H. Allocative efficiency vs. X-efficiency. American Economic Review, v. 56, n. 3, p. 392-415, 1966. 
- A oferta de táxis tende a crescer quando as restrições de entrada são removidas. Os entrantes individuais focam nos segmentos de ponto e circulação em vias, mesmo porque no segmento de porta a porta a tendência é a ampliação da oferta pelos operadores já existentes. No que diz respeito ao aumento de táxis pós-desregulação de entrada, cidades norte-americanas apresentaram crescimento entre 18\% (Kansas City, 1983/1984) e 127\% (San Diego, 1979);

- Caso as tarifas continuem a ser reguladas após a desregulamentação da entrada, o setor de transporte privado individual de passageiros (caronas pagas, por exemplo) continuaria a operar como um complemento aos táxis no segmento porta a porta por meio de chamadas telefônicas;

- Processos de desregulamentação graduais parecem ter gerado melhores resultados que processos de desregulamentação simultâneos de entrada e tarifas. Isso ocorre por conta dos efeitos inesperados causados pelas mudanças regulatórias. O processo de desregulamentação do mercado de táxis na Holanda é considerado um exemplo bem-sucedido, embora se tenha uma avaliação de que nem todos os seus objetivos tenham sido plenamente alcançados;

- A perda de qualidade da frota de veículos não parece estar associada à livre entrada, assim como uma regulação muito forte não parece ser capaz de evitar deterioração da qualidade dos serviços. Contudo, os padrões de qualidade dos serviços devem ser endereçados independentemente do modelo regulatório desejado.

Em suma, o modelo de equilíbrio parcial aplicado à questão da desregulamentação dos mercados de táxis é capaz de providenciar fatos estilizados condizentes com a realidade das alterações observadas nos mercados desregulamentados, mas em outras situações providencia predições não observáveis empiricamente, como é o caso da redução esperada nos preços, sendo que na prática o que se observa é o aumento dos preços e da variabilidade dos serviços prestados. Isso ocorre porque em geral é assumido que o agente regulador estabelece preços corretos de equilíbrio, sendo que na realidade, na maioria dos casos avaliados pela literatura, os preços máximos represavam potenciais aumentos. 


\section{Análise de equilíbrio urbano}

\section{O modelo neoclássico de equilíbrio urbano}

Sob a ótica da economia, a formação da cidade decorre da concentração de empregos, que por sua vez implica na concentração espacial de residências nas imediações dos locais de trabalho. As duas principais forças econômicas que conduzem a concentração urbana são as economias de escala e as economias de aglomeração. As economias de escala ocorrem dentro das firmas e estão relacionadas ao fato do custo marginal de produção ser declinante à medida que o nível de produção aumenta. Já as economias de aglomeração são externas à firma e decorrem da internalização de benefícios incorridos por sua proximidade com outras firmas (clientes e fornecedores), bem como de uma ampla estrutura de provisão de bens públicos.

As economias de escala e as economias de aglomeração são determinantes centrais na decisão de localização das firmas. Os custos de transporte (de mercadorias ou de pessoas) também influenciam a decisão de localização das firmas, podendo conduzir ou até mesmo reforçar a concentração espacial dos empregos. Logo, podemos inferir que os custos de transporte podem exercer (direta ou indiretamente) papel fundamental na concentração espacial, na configuração das cidades e no uso e ocupação do solo urbano. O objetivo da presente seção é apresentar o modelo neoclássico de economia urbana, que tem como um de seus desdobramentos mostrar como os custos de locomoção das pessoas nas cidades podem moldar, transformar ou alterar a configuração das cidades.

Os trabalhos sobre economia urbana nasceram na década de 1960. As contribuições seminais são atribuídas a Alonso (1964), ${ }^{32}$ Muth (1969) ${ }^{33}$ e Mills (1967), ${ }^{34}$ de forma que o modelo neoclássico de economia urbana é conhecido como Alonso-Muth-Mills, ou modelo urbano monocêntrico. O objetivo central de tais modelos era o de providenciar fatos estilizados, ou seja, providenciar uma aproximação teórica de fenômenos urbanos observáveis empiricamente, tais como: comparado com regiões periféricas, os centros das cidades são mais densamente povoados, com habitações menores, edificações mais altas

\footnotetext{
ALONSO, W. Location and land use. Cambridge: Harvard University Press, 1964.

MUTH, R. F. Cities and housing. Chicago: University of Chicago Press, 1969.

34 MILLS, E. S. Studies in the structure of the urban economy. Baltimore: Johns Hopkins University Press, 1972.
} 
e preços por metro quadrado mais elevados; as regiões centrais são constituídas por habitações em edifícios (apartamentos), enquanto as habitações nas periferias são térreas (casas).

Como veremos, o modelo neoclássico de economia urbana de AlonsoMuth-Mills fornece uma boa aproximação das cidades monocêntricas. Por outro lado, o modelo tem sido criticado por conta do fato das cidades tornarem-se crescentemente policêntricas ao longo das últimas décadas. Contudo, partilho da visão de Kraus (2006), ${ }^{35}$ de que mesmo apresentando dificuldades em providenciar uma aproximação teórica satisfatória para a realidade das cidades policêntricas, a monocentricidade continua sendo uma boa aproximação para uma grande parte das áreas urbanas do mundo; e que as forças econômicas que surgem das cidades monocêntricas são igualmente fundamentais para analisar os casos das cidades policêntricas, de modo que o modelo monocêntrico fornece um bom ponto de partida analítico.

O modelo matemático apresentado ao longo da presente seção foi desenvolvido por Brueckner (1987), ${ }^{36}$ porém uma versão mais simplificada (abordagem gráfica) pode ser encontrada em Brueckner (2011). ${ }^{37}$

\section{O Modelo Alonso-Muth-Mills}

Na cidade estilizada, representada pelo modelo, cada residente se desloca para trabalhar no centro da cidade, aqui denominado de CBD (iniciais de central business district). $\mathrm{O}$ custo de deslocamento por quilômetro de ida e volta do trabalho é igual a $t$, de modo que o custo de se deslocar a uma distância radial de $x$ quilômetros do CBD é de $t x$ por período (CBD é o ponto onde $x=0)$.

Os consumidores são homogêneos em termos de gostos e preferências (funções utilidade similares) e são remunerados igualitariamente, com uma renda igual a $y$ por período. As preferências dos consumidores são representadas por uma função utilidade estritamente quase-côncava $v(c, q)$,

35 KRAUS, M. Monocentric cities. In: ARNOTT; MCMILLEN (ed.). A companion to urban economics. Cambridge: Blackwell Publishing, 2006.

36 BRUECKNER, J. The structure of urban equilibria: a unified treatment of the Muth-Mills model. In: MILLS (ed.). Handbook of regional and urban economics. Amsterdã: Elsevier Science, 1987.

37 BRUECKNER, J. Lectures on urban economics. Cambridge: MIT Press, 2011. 
onde $c$ é o consumo de uma cesta de bens e serviços e $q$ é o consumo de habitação, especificado em metros quadrados de espaço físico. ${ }^{38}$

O preço da cesta de bens e serviços (numerário) é o mesmo em qualquer parte da cidade. Já o preço do aluguel de $q$ metros quadrados de habitação é igual a $p$ e varia conforme a localização da habitação do residente. Como os consumidores são idênticos, o equilíbrio urbano deve implicar níveis de utilidade idênticos para todos os residentes da cidade, independentemente de quão próximos ou distantes estejam do CBD. A variação espacial de $p$ é o componente-chave para equalização das utilidades entre moradores em quaisquer pontos da cidade, ou seja, garante que um indivíduo que habite no $\mathrm{CBD}$, onde $x=0$, disponha da mesma utilidade de um indivíduo que habite na periferia, onde $x>0$.

Dadas as hipóteses acima, o problema do habitante/consumidor é:

$$
\begin{aligned}
& \max _{\{q\}} v(c, q)=u \\
& \text { Sujeito a } c+p q=y-t x
\end{aligned}
$$

A condição de primeira ordem deste tipo de problema de maximização utilidade sujeita a uma restrição orçamentária é bem conhecida na literatura:

$$
\frac{v_{2}(c, q)}{v_{1}(c, q)}=p
$$

Onde os subscritos denotam as derivadas parciais.

Na equação [2] temos a situação na qual a taxa marginal de substituição entre $q$ e $c$ é igual à razão entre seus preços. Em termos gráficos, isso equivale ao bem conhecido ponto de tangência da função utilidade com a reta de restrição orçamentária.

O requerimento adicional de equilíbrio espacial é que a cesta de consumo resultante deva garantir uma mesma utilidade $u$ para qualquer um dos habitantes/consumidores da cidade, ou seja:

38 Por simplicidade, o único atributo considerado para alugar um imóvel é o espaço físico em metros quadrados. 


$$
v(y-t x-p q, q)=u
$$

Com o sistema de equações [2] e [3] é possível achar os valores para as incógnitas do modelo: $p$ e $q$. Já tais valores de solução dependem dos demais parâmetros $x, y, t$ e $u$. Em suma, o custo de deslocamento $t$ afeta os preços dos imóveis (aluguéis), bem como a demanda por metros quadrados de habitação na cidade.

A natureza da dependência de $p$ e $q$ sobre os parâmetros $x, y, t$ e $u$ pode ser derivada matematicamente pela diferenciação total a partir das equações [2] e [3], por exemplo:

$$
\begin{gathered}
\frac{\partial u}{\partial c} \frac{\partial c}{\partial x}+\frac{\partial u}{\partial q} \frac{\partial q}{\partial x}=-v_{1}\left(t+\frac{\partial p}{\partial x} q+\frac{\partial q}{\partial x} p\right)+v_{2} \frac{\partial q}{\partial x}=0 \\
\frac{\partial p}{\partial x}=-\frac{t}{q}<0
\end{gathered}
$$

Em suma, o preço do aluguel por metro quadrado de habitação é uma função decrescente da distância para o CBD.

O mesmo exercício pode ser aplicado para verificarmos o impacto de um aumento de $x$ em $q$, de modo que a solução é igual a:

$$
\frac{\partial q}{\partial x}=\theta \frac{\partial p}{\partial x}>0
$$

Onde $\theta<0$ é a inclinação da curva de demanda compensada.

Da equação [6] temos que os metros quadrados de habitação são uma função crescente da distância para o CBD, ou seja, as habitações na periferia da cidade tenderiam a ser maiores (em termos de metros quadrados per capita) em relação às habitações localizadas no CBD. Em suma, o modelo providencia 
uma aproximação teórica bastante satisfatória da evidência empírica encontrada na maioria das cidades monocêntricas ao redor do mundo.

O autor providencia uma seção do artigo apenas para derivar os efeitos do aumento do custo de deslocamento por quilômetro de ida e volta do trabalho $(t)$ sobre as variáveis-chave do modelo. Os resultados são sintetizados abaixo: - Todas as viagens realizadas dentro da cidade se tornarão mais caras e a cidade reduzirá seu tamanho como resposta;

- Aumentarão: (i) o preço do metro quadrado dos aluguéis residenciais; e (ii) a densidade estrutural no $\mathrm{CBD}$. Por outro lado, serão reduzidos os valores destas mesmas variáveis para os pontos mais distantes do CBD, ou seja, nas áreas periféricas da cidade;

- O tamanho das habitações será reduzido no $\mathrm{CBD}$, porém poderá crescer nas áreas periféricas da cidade.

Em se tratando da regulamentação de transporte nas cidades, devemos ter clareza de qual o efeito que tal ato regulatório exercerá sobre o custo de deslocamento das pessoas, pois tal ato não afetará apenas o mercado de transportes, mas também trará potenciais implicações sobre as demais variáveis do espaço urbano, tais como o uso e a ocupação do solo urbano. A próxima seção buscará elucidar em maiores detalhes quais os efeitos de variações de custos de deslocamentos em uma área urbana.

\section{Sprawl urbano e externalidades}

Em termos gerais, o sprawl urbano (ou espraiamento urbano) é caracterizado por alguns padrões de uso e ocupação do solo urbano, dentre eles: (i) desenvolvimento em áreas com baixa densidade populacional, geralmente por meio do uso e da ocupação de áreas até então agricultáveis nos limites das cidades; (ii) efeito "scattered development", ou seja, ênfase na segmentação e especialização do uso do solo, onde grandes áreas são exclusivamente dedicadas ou para uso comercial, ou para uso industrial, ou ainda para uso residencial, em oposição às composições mistas encontradas nas áreas centrais das cidades; e (iii) efeito "leapfrog development", ou seja, áreas de solo vagas entre aglomerações urbanas localizadas nas franjas das cidades. Tal efeito é geralmente motivado por questões de especulação imobiliária..$^{39}$

39 Archer, R. Land Speculation and scattered development; failures in the urban-fringe land market. Urban Studies, v. 10: 367-372, 1973. 
Os problemas associados com o sprawl urbano podem ser de natureza econômica, ambiental ${ }^{40}$ e até mesmo de saúde pública. ${ }^{41}$ Dentre os problemas ambientais, um de especial destaque é o aumento do escoamento das águas pluviais, além do agravamento gerado pelo espraiamento das cidades nas periferias, onde geralmente são concentrados os mananciais. ${ }^{42}$ Outros problemas ambientais incluem: redução da diversidade de espécies, aumento do risco de enchentes e inundações, remoção excessiva de vegetação nativa, fragmentação de ecossistemas etc.

Já no que diz respeito aos problemas de saúde associados ao sprawl urbano, podemos elencar: aumento de incidência de doenças associadas à inatividade física (doenças do coração, diabetes, câncer de cólon e osteoporose), redução da qualidade do ar (doenças respiratórias, do coração e alguns tipos de câncer), acidentes com colisões de veículos automotores (traumas e ferimentos, fatais ou não), isolamento social e estresse (impactos de saúde mental).

Retornando ao ponto central da discussão, verificamos que a redução dos custos de deslocamento dentro de uma cidade - decorrentes, por exemplo, de maior competição, desregulamentação com livre entrada e saída de concorrentes - podem trazer grandes benefícios para os consumidores, mas não é possível descartar a possibilidade de que também tragam efeitos colaterais para o bem-estar do conjunto de habitantes das cidades.

Os argumentos de equilíbrio parcial favoráveis à expansão do mercado de caronas pagas mediados por aplicativos de smartphones repousam exclusivamente sobre os benefícios ao grupo de consumidores daquele mercado. Contudo, a questão central é: deveriam os gestores e legisladores locais focarem políticas públicas baseadas exclusivamente na maximização do bemestar de determinados grupos de consumidores?

Em suma, sob a ótica das políticas anti-sprawl e políticas urbanas, melhorar o bem-estar de um grupo de consumidores por conta da redução de seus custos de deslocamento por meio de transporte individual (público

40 Johnson, M. Environment impacts of urban sprawl: a survey of the literature and proposed agenda. Environment and Planning, v. 33: 717-735, 2001.

41 Alberta Health Services (2009). Urban sprawl and health. Health public police information sheet. Disponível em: <http://www.albertahealthservices.ca/poph/hi-poph-hpp-info-urbansprawl.pdf>.

42 Este tópico é tratado com bastante detalhamento em: Tucci, C. (2005). "Gestão das águas pluviais urbanas". Mimeo Ministério das Cidades - Global Water Partnership - World BankUnesco. 
ou privado) não é condição necessária e suficiente para que o conjunto da sociedade também desfrute de maior bem-estar, principalmente quando inferimos tais efeitos a partir de modelos dinâmicos com gerações sobrepostas. Isso ocorre porque o consumo de determinados bens pode gerar externalidades negativas, tais como poluição (sonora, visual, atmosférica, do solo e da água), congestionamento de bens públicos etc.

Vários tipos de consumo geram externalidades, várias delas negativas, muitas das quais os consumidores sequer têm noção de que existam e muito menos condições de mensurar para internalizá-las. A não internalização das externalidades pode implicar em várias ineficiências econômicas, uma vez que os preços de mercado são inferiores aos socialmente desejáveis, pois não compensam a perda de bem-estar causada pela externalidade (o consumo é subsidiado pelo valor das externalidades).

Outra implicação de mercados com externalidades é que os preços menores tendem a gerar maiores quantidades comercializadas (equilíbrio entre oferta e demanda), de forma que mais recursos que o socialmente desejável (capital, trabalho etc.) são alocados para aquele mercado, sendo que poderiam ser usados de forma mais eficiente em outros setores.

\section{Equilíbrio geral urbano e políticas urbanas}

A ciência econômica, a engenharia, a arquitetura e o urbanismo fornecem um conjunto de elementos analíticos para a mensuração e a simulação de potenciais efeitos decorrentes de mudanças na estrutura de oferta de transporte urbano (individual ou coletivo) de passageiros, suas implicações, bem como um rol de proposições de políticas públicas mitigadoras de eventuais efeitos adversos.

Os modelos urbanos de previsão, conhecidos como modelos Luti (Land Use Transport Interaction), são modelos matemáticos de simulação que combinam teoria, dados e algoritmos que providenciam uma representação abstrata da interação entre o transporte e o uso do solo urbano. ${ }^{43} 44$ Tais modelos estão disponíveis na literatura desde a primeira metade da década de 1960,

43 TORRENS, P. How land-use transportation models work. London: Centre for Advanced Spatial Analysis, 2000.

44 COPPOLA, P. et al. Luti model for the metropolitan area of Santander. Journal of Urban Planning and Development, v. 139, p. 153-165, 2013. 
quando Ira Lowry desenvolveu o trabalho intitulado "A model of metropolis", publicado como memorando para a Rand Corporation..$^{45} \mathrm{O}$ modelo de Lowry fez parte de um estudo econômico para a região de Pittsburgh e era formado por um sistema de equações com três setores: um setor básico (formado por estabelecimentos industriais, comerciais e administrativos exportadores de bens e serviços para famílias e empresas não residentes na região modelada); um setor varejista (formado por estabelecimentos industriais, comerciais e administrativos provedores de bens e serviços para famílias e empresas residentes na região modelada); e um setor residencial. O modelo descrevia a organização espacial das atividades e buscava modelar impactos de políticas e mudanças no crescimento populacional, no padrão do emprego e na eficiência do sistema de transportes.

Entre a década de 1960 até o presente momento os modelos do tipo Luti já passaram por três gerações, sendo que a primeira geração apareceu entre as décadas de 1960 e 1970, e podiam ser divididos em três tipos: (i) os modelos espaciais e gravitacionais, baseados na teoria da interação espacial, do qual faz parte o trabalho clássico de Lowry; (ii) os modelos de programação matemática baseados em técnicas de otimização; e (iii) os modelos baseados em matrizes de insumo-produto. Já os modelos de segunda geração datam das décadas de 1980 e 1990, sendo modelos de escolha discreta, baseados na teoria da utilidade randômica de McFadden (1974). ${ }^{46}$ Finalmente, os modelos de terceira geração surgem a partir da segunda metade da década de 1980 e têm como característica serem modelos altamente desagregados, dinâmicos e viabilizarem a construção de exercícios de microssimulação.

Um dos modelos do tipo Luti mais conhecidos entre os economistas é o modelo Relu-Tran (Regional Economy, Land Use and Transportation Model) ${ }^{47}$ desenvolvido por Alex Anas, professor de economia na Universidade Estadual de Nova Iorque, em Buffalo. A grande vantagem do Relu-Tran é o setor governo, que possibilita o controle de vários instrumentos fiscais, tais como imposto sobre a renda, imposto sobre a propriedade, pedágios pigouvianos sobre congestionamentos de tráfego, pedágios para ingresso em centros urbanos, tarifas de estacionamentos e impostos sobre combustíveis.

45 Uma versão digitalizada do artigo original pode se encontrar em: <www.casa.ucl.ac.uk/rits/ lowry.pdf>.

46 MCFADDEN, D. Conditional logit analysis of qualitative choice behaviour. Edição de P. Zarembka. New York: Academic Press, 1974.

47 Ver detalhes na página institucional do projeto em: <https://sites.google.com/site/alexanas homepage/the-relu-tran-model-and-its-applications $>$. 
O setor governo do modelo Relu-Tran também possibilita controlar a política de zoneamento, a extensão do cinturão verde etc.

A grande maioria das cidades não dispõe de modelos de simulação do tipo Luti, nem mesmo muitas das metrópoles localizadas nas principais economias industrializadas do mundo. Contudo, o progresso tecnológico tem propiciado a produção e comercialização de computadores e softwares com capacidade de manipulação de grandes quantidades de dados a custos declinantes. A própria dificuldade em obter dados tem sido desafiada pelas novas técnicas e metodologias de coletar dados urbanos pela internet (data mining ${ }^{48}$ e web scraping ${ }^{49}$ ), além dos próprios dados georreferenciados obtidos em serviços prestados por meio de aplicativos de smartphones.

Seria desejável que as autoridades locais buscassem aprimorar ao máximo seus mecanismos de coleta e processamento de informações, bem como de seus instrumentos de inteligência analítica, de modo que possam fornecer respostas mais rápidas, eficientes e efetivas a eventos disruptivos que tragam implicações diretas ou indiretas para o dia a dia das cidades.

A construção de tal inteligência é fundamental para que as autoridades locais e os legisladores disponham de informações que sirvam de suporte para formulação de políticas públicas, tomada de decisão e respostas a choques idiossincráticos (desastres naturais, por exemplo) e eventos disruptivos. No caso específico da gestão de uma política de formação de um mercado estruturado de caronas pagas, as respostas para algumas questões são fundamentais:

- Qual a previsão e a meta da frota de veículos operando no mercado de caronas pagas naquela cidade?

- Qual o impacto em termos de carros adicionais nas ruas? Seria apenas efeito substituição da frota já existente?

- Um carro dedicado à carona paga substituiria quantos carros particulares que tomariam espaço de estacionamentos nos centros urbanos?

- Caso adicione carros nas ruas, qual seria a estimativa de frota adicional? Quais serão as regiões da cidade mais afetadas? Qual a implicação em termos de consumo adicional de bens públicos? Haveria aumento de congestionamentos e de poluição?

48 BEHNISCH, M.; ULTSCH, Alfred. Urban data mining using emergent SOM. In: PREISACH et al. (ed.). Data analysis, machine learning and applications. Springer Berlin Heidelberg, 2008.

49 Exemplos de projetos disponíveis na página institucional do D-Lab da Univeridade da Califórnia, Berkeley: <http://dlab.berkeley.edu/>. 
- Caso haja o risco de aumentar a frota de veículos nas ruas, podendo implicar no aumento de congestionamentos e poluição, quem arcaria com o custo das externalidades de consumo dos serviços de caronas pagas?

- Seria possível acomodar potenciais efeitos adversos com o mero remanejamento do trânsito? Seriam necessários investimentos adicionais em infraestrutura viária?

- Seria necessário e/ou estratégico reformular o plano de zoneamento das cidades para acomodar o novo serviço ao menor custo social possível? Ou isso nem seria necessário, pois seus impactos seriam negligenciáveis?

As respostas para tais perguntas são fundamentais para a análise de custos e benefícios da autoridade local, inclusive para tratar de eventual desregulamentação do mercado de transporte individual de passageiros, pois a não internalização de potenciais externalidades tornariam o custo dos serviços de transporte individual de passageiros mais econômicos do que o socialmente desejável, tornando a oferta do serviço desnecessariamente maior. Em suma, toda a sociedade arcaria com o ônus da externalidade em prol do aumento de bem-estar dos consumidores de serviços de transporte individual de passageiros.

\section{Conclusões}

Ao longo do presente trabalho foi visto que as soluções tecnológicas propiciadas pelos aplicativos de smartphones têm endereçado vários dos problemas que justificavam e serviram historicamente como argumentos favoráveis para a regulação de táxis, principalmente no que diz respeito ao segmento porta a porta. A autorregulação imposta aos motoristas de caronas pagas pelas empresas de tecnologia tem garantido credibilidade de bons serviços prestados, de modo que tem criado rivalidade aos mercados de táxis, motivando reações controversas por parte das autoridades e dos legisladores locais, além dos próprios taxistas. Tal fato tem despertado na sociedade a reflexão sobre a real necessidade de mantermos uma regulação para tal mercado.

A lógica da desregulamentação e busca por políticas liberalizantes decorre fundamentalmente de uma ótica econômica de equilíbrio parcial, nos moldes da análise microeconômica clássica de bem-estar, onde o excedente do consumidor é claramente reduzido por conta do peso morto das restrições impostas pela regulação. Os consumidores toleram a regulação por 
considerarem que o mercado apresenta falhas, principalmente decorrentes de assimetria de informação. Contudo, quando tais falhas são solucionadas, a regulação perde sentido e o movimento refratário dos reguladores seria basicamente motivado pela captura regulatória.

Tal argumento é muito potente sob duas hipóteses: (i) o avanço tecnológico fará com que o mercado de táxis se limite ao segmento porta a porta por meio de chamadas telefônicas; e (ii) o consumo de viagens por meio de transporte individual de passageiros não gera externalidades negativas. A primeira hipótese parece ser menos restritiva, pois, como foi mencionado ao longo do texto, na metade da década de 1990 tal segmento já correspondia a $70 \%$ do mercado de táxis em países desenvolvidos.

Uma limitação da análise de equilíbrio parcial é desconsiderar o fato de que as variações nos custos de deslocamento dentro das áreas urbanas podem alterar a configuração das cidades, bem como o uso e a ocupação do solo urbano. Em suma, podem afetar outras variáveis relevantes do espaço urbano, tais como os preços dos imóveis, dos aluguéis residenciais e até mesmo a taxa de crescimento e espraiamento das cidades (sprawl urbano), além de outras externalidades, como potencial aumento de congestionamentos de bens públicos e diferentes tipos de poluição.

Sob a ótica da análise de equilíbrio urbano, o próprio argumento da captura regulatória deveria ser relativizado. Gestores urbanos tendem a focar políticas que possam gerar incentivos para que as pessoas substituam o transporte individual de passageiros (públicos ou privados) por transporte coletivo. Neste sentido, buscam reduzir custos pecuniários (subsídios) e de oportunidade (aumento na velocidade de deslocamento) dos transportes coletivos e imputam custos adicionais aos veículos que servem de transporte individual de passageiros. Tais políticas não guardam nenhuma relação com captura no mercado de táxis.

Deixando de lado as análises econômicas de equilíbrios parcial e geral, a história sugere que a trajetória dos transportes urbanos foi marcada por " public takeovers", ou seja, tais serviços nasceram privados e se tornaram públicos por conta de suas imperfeições de mercado (assimetria de informação, externalidades etc.). A própria regulação de táxis, como visto, foi instituída na cidade de Nova Iorque em resposta ao grande número de motoristas que passaram a circular por longas horas nas ruas em busca de clientes, gerando vários problemas. Por outro lado, a história mostra que a captura regulatória também esteve presente neste processo. 
Por outro lado, como visto ao longo do texto, a experiência de desregulamentação dos mercados de táxis providencia exemplos para todos os gostos e preferências, desde o fato de os mercados de táxis serem historicamente marcados por processos cíclicos de regulação e desregulamentação, até o bem-sucedido caso holandês - considerado um caso benchmark na literatura especializada.

Como os casos bem-sucedidos e malsucedidos de desregulamentação coexistem na literatura, podemos inferir que o processo de "como fazer" tem papel fundamental em tais tipos de políticas. Contudo, o processo depende das especificidades e das idiossincrasias de cada um dos mercados a serem desregulamentados. Foi visto ao longo do texto que os mercados de táxis dependem muito de outras características das cidades, tais como o uso e ocupação do solo, a rede de transporte coletivo, as diferentes distribuições de densidades populacionais em vários bairros etc. Portanto, uma norma regulatória transversal a ser aplicada indiscriminadamente em cidades heterogêneas deve ser considerada com a devida cautela.

Um dos argumentos que justifica o êxito do processo de desregulamentação do mercado de táxis na Holanda é que o processo foi gradual. De fato, mercados que geram externalidades tendem a ser regulados e configurados com várias políticas do tipo "second best", muitas vezes articuladas e interrelacionadas entre si. Parte da dificuldade do processo de barganha na eliminação regulatória decorre deste fato, o que gera evidente preocupação e incerteza para as autoridades, sem que isso tenha, novamente, qualquer relação com captura. Caso a literatura fosse unânime em apontar a desregulamentação como uma solução invariavelmente superior, de fato movimentos refratários decorreriam exclusivamente de captura, mas a evidência empírica disponível sugere que não é este o caso.

Contudo, analisando em detalhe o caso holandês, talvez consigamos verificar outras virtudes, tal como a supermodularidade da estratégia. Os holandeses não apenas desregulamentaram o mercado de táxis, mas também criaram incentivos para que tal mercado operasse em consonância com as outras políticas urbanas. Por exemplo, o mercado de táxis foi estimulado a operar como um modal interligado à rede de transporte coletivo das cidades, contrapondo a lógica de que os táxis são substitutos dos veículos particulares e que concorrem com o transporte coletivo (argumento que tem sido desafiado pela evidência empírica recente). Em suma, os holandeses compatibilizaram os benefícios trazidos pela desregulamentação do mercado de táxis (análise de equilíbrio parcial) com os demais objetivos dos planejadores urbanos (análise de equilíbrio urbano). 
Finalmente, é necessário discutir a regulação do mercado de transporte individual de passageiros, visto que não há elementos econômicos que justifiquem a proibição de novos prestadores de serviços de transporte individual. Para além disso, elementos econômicos sugerem que, sob uma ótica concorrencial e do consumidor, a atuação de novos agentes tende a ser positiva.

\section{Referências bibliográficas}

AARHAUG, J.; SKOLLERUD, K. Taxi: different solutions in different segments. European Transport Conference. Frankfurt, 2013.

ALBERTA HEALTH SERVICES Urban sprawl and health. Health public police information sheet. 2009. Disponível em: <www.albertahealthservices.ca/ poph/hi-poph-hpp-info-urban-sprawl.pdf>.

ALONSO, W. Location and land use. Cambridge: Harvard University Press, 1964.

ARCHER, R. Land speculation and scattered development; failures in the urban-fringe land market. Urban Studies, v. 10, p. 367-372, 1973.

BAANDERS, A.; CANOY, M. Ten Years of Taxi Deregulation in the Netherlands - the case for re-regulation and decentralization. European Transport Conference, 2010 Proceedings. 2010.

BEHNISCH, M.; ULTSCH, Alfred. Urban data mining using emergent SOM. In: PREISACH et al. (ed.). Data analysis, machine learning and applications. Springer Berlin Heidelberg, 2008.

BEKKEN, J.; LONGVA, F. Impact of taxi market regulation. TOI Report, Oslo, Norway, 2003.

BRUECKNER, J. The structure of urban equilibria: a unified treatment of the Muth-Mills model In: MILLS (ed.). Handbook of regional and urban economics. Amsterdã: Elsevier Science, 1987.

BRUECKNER, J. lectures on urban economics. Cambridge: MIT Press, 2011.

COPPOLA, P. et al. Luti model for the metropolitan area of Santander. Journal of Urban Planning and Development, v. 139, p. 153-165, 2013. 
DEMPSEY, P. Taxi industry regulation, deregulation, and reregulation: the paradox of market failure. Transportation Law Journal, v. 24, n. 1, p. 73-120, 1996.

FREITAS, P. Quem ganha e quem perde com a liberação dos táxis? Brasil: economia e governo. 2015. Mimeo.

HODGES, G. Taxi! A social history of the New York City cabdriver. Baltimore, Maryland: The John Hopkins University Press, 2007.

JOHNSON, M. Environment impacts of urban sprawl: a survey of the literature and proposed agenda. Environment and Planning, v. 33, p. 717-735, 2001.

KRAUS, M. Monocentric cities. In: ARNOTT; MCMILLEN (ed.). A companion to urban economics. Cambridge: Blackwell Publishing, 2006.

KRUEGER, A. The political economy of the rent-seeking society. American Economic Review, v. 64, n. 3, p. 291-303, 1974.

LEIBENSTEIN, H. Allocative efficiency vs. X-efficiency. American Economic Review, v. 56, n. 3, p. 392-415, 1966.

MCFADDEN, D. Conditional logit analysis of qualitative choice behaviour. Edição de P. Zarembka. New York: Academic Press, 1974.

MILGROM, P.; ROBERTS, J. Complementarities and fit strategy, structure, and organizational change in manufacturing. Journal of Accounting and Economics, v. 19, n. 2-3, p. 179-208, 1995.

MILLS, E. S. Studies in the structure of the urban economy. Baltimore: Johns Hopkins University Press, 1972.

MUTH, R. F. Cities and housing. Chicago: University of Chicago Press, 1969.

OECD (2007). Taxi services: competition and regulation. Policy Roundtables. DAF/COMP (2007) 42.

SCHALLER, B. A regression model of the number of taxicabs in U.S. cities. Journal of Public Transportation, v. 8, n. 5, p. 63-78, 2005.

STEG, L. Can public transport compete with the private car? IATSS Research, v. 27, n. 2, p. 27-35, 2003.

TONER, J. Regulation in the taxi industry. ITS Working Paper 381, Institute for Transport Studies, University of Leeds, Leeds, 192. 
TORRENS, P. How land-use transportation models work. London: Centre for Advanced Spatial Analysis, 2000.

TUCCI, C. Gestão das águas pluviais urbanas. Mimeo. Ministério das Cidades - Global Water Partnership - World Bank - Unesco, 2005.

TULLOCK, G. The welfare costs of tariffs, monopolies, and theft. Western Economic Journal, v. 5, n. 3, p. 224-232, 1967.

VARIAN, H. (2000). Microeconomia: princípios básicos. 5. ed. Campus, 2000. cap. 32.

VUCHIC, V. Urban transit: operations, planning and economics. Hoboken, New Jersey: John Wiley \& Sons, Inc., 2005. 